\title{
Long QT: The art of measurement
}

\author{
Ali Naderi Mahabadi ${ }^{*}$, Dinesh Sharma ${ }^{1}$ and Elizabeth Kaufman ${ }^{2}$ \\ ${ }^{1}$ Department of Cardiology, Case Western Reserve, MetroHealth Medical Center in Cleveland, Ohio, USA \\ ${ }^{2}$ Cardiologist, MetroHealth Medical Center in Cleveland, Ohio, USA
}

\begin{abstract}
The QT interval represents the time it takes for the ventricles to depolarize and repolarize. Accurate measurement is essential for many clinical decision-making situations, which can significantly affect patient outcomes. Prolonged QRS duration in cases such as paced rhythm, LVH and conduction abnormalities pose significant challenges in accurately measuring the QT interval. This review will focus on how to accurately measure the QT interval and how to avoid common pitfalls.
\end{abstract}

\section{Introduction and background}

QT interval measurement is one of the most important aspects of any electrocardiogram (ECG) evaluation. It has significant clinical importance, as there is a correlation between the QT interval length and the risk of developing ventricular tachyarrhythmias.

The importance of the QT interval did not come to light for several decades after the invention of the ECG by Willem Einthoven in the early $20^{\text {th }}$ century. Louise Wolff, an American cardiologist who described the WPW syndrome with Parkinson and White, was probably the first person to measure the QT interval [1]. However, the clinical importance of the QT interval was not fully understood until further work by Jervell and Lange-Nielsen in the late 1950s, and Romano, Gemme, Pongiglione, and Ward in the 1960s [2,3]. Several types of long QT syndrome have since been described, and the awareness and knowledge of the relationship between QT prolongation and torsades de pointes has since grown. In 2007, the FDA formed an Internal Review Team (IRT) with the responsibility to oversee the clinical assessment of QT prolongation for all drugs that the agency reviewed. Assessment of QT prolongation has rapidly become an essential part of the development of new drugs [4]. It is now common practice to measure and monitor the QT interval with the use of many drugs, especially the antiarrhythmic agents. Despite the advent of many computer-assisted algorithms and software programs, the accurate measurement of QT interval remains a challenge for many clinicians. A survey of 334 practitioners, the majority of whom specialize in cardiology (81\%), showed that $61 \%$ were able to identify what represented the QT interval on an ECG and only $36 \%$ were able to measure the QT interval [5].

\section{QT interval}

The QT interval is measured from the beginning of the QRS complex until the end of the T wave. It is the measure of both ventricular depolarization (QRS complex) and ventricular repolarization (JT segment) with the latter having more importance with respect to arrhythmias related to abnormal repolarization.

Depolarization is primarily the result of fast inward sodium current through the sodium channels (INa) while repolarization is due to the interaction between inward sodium current (INa), slow inward calcium current (ICa-L) and outward current through the slowly activating (IKs) and rapidly activating (IKr) delayed rectifier potassium channels [6]. Changes in function of these channels (loss of function of the outward currents or gain of function of the inward currents) will change the current density and result in change in QRS and QT interval.

Several factors affect the QT interval and its accurate measurement and interpretation. Factors that affect delay in ventricular depolarization (bundle branch block, paced rhythm, pre-excitation and use of class IC antiarrhythmic drugs) intrinsically affect the QT interval and must be considered when assessing the QT interval for abnormal repolarization. Gender and heart rate need to be considered when interpreting the QT interval [7].

\section{QT measurement methods}

Automatic measurements routinely made on the 12-lead ECG are often inaccurate. Therefore, manual measurement is necessary [8]. Most automated machines measure all the leads simultaneously, and the reported interval is usually longer than any individual lead [9]. Different manufacturers use different computerized methods. Some use a digitizing pad, magnifying lamp, and pointing device to identify the beginning and end of the QT interval, with an accuracy level of $5 \mathrm{~ms}$ [8]. A more advanced method is to use digital screens where computerdriven calipers can perform the measurement [8].

For the manual measurement, a standard 12-lead ECG with a 25 $\mathrm{mm} / \mathrm{s}$ paper speed, and $10-\mathrm{mm} / \mathrm{mV}$ amplitude is usually used. A faster paper speed, such as $50 \mathrm{~mm} / \mathrm{s}$, can provide even better resolution. Several factors affect the accurate measurement of the QT interval. These include the correct identification of QRS complex initiation, the end of $T$ wave, exclusion of $U$ waves and identifying the correct lead for the measurement. The leads with the longest QT should be used, which are usually leads II and V5 since the P-QRS-T vector axis is in the direction of those two leads. However, Lead II only has the longest QT about $60 \%$ of the time [10]. Other leads such as III, V1, aVF and aVL

${ }^{\star}$ Correspondence to: Ali Naderi, Department of Cardiology, Case Western Reserve, MetroHealth Medical Center in Cleveland, Ohio, USA, E-mail: naderi.m@gmail.com

Received: June 08, 2019; Accepted: June 19, 2019; Published: June 24, 2019 
have been suggested because they are more likely to have measurable QT intervals [11].

One study showed that if lead II could not be used due to poor quality, leads aVF and aVR would be the best alternatives to lead II as their axis are closest to lead II [12].

One single lead should not be used if the tracing is uninterpretable in that lead [10]. When possible, QT should be measured in multiple leads (all leads with a measurable QT interval) and checked for consistency.

The AHA/ACCF/HRS 2009 scientific statement on recommendations for the standardization and interpretation of the electrocardiogram recommends using lead V2 or V3 unless measurement differs by more than $40 \mathrm{~ms}$ from that in other leads, in which case measurements from adjacent leads should be considered [9]. In the presence of a prominent $U$ wave, it is recommended that leads without $U$ waves (usually aVR and aVL) be used [13]. There are several methods to perform manual measurement of the QT interval [15].

\section{Threshold method}

In this method, the end of the QT interval is defined as the intersection of the terminal end of the $\mathrm{T}$ wave with the isoelectric line. If a $U$ wave interrupted the terminal portion of the $T$ wave, then the terminal portion is defined as the nadir between $\mathrm{T}$ and $\mathrm{U}$ waves [15].

\section{Tangent method}

In this method, a line is drawn from the peak of the $\mathrm{T}$ wave through the steepest section of the descending part of the $T$ wave. The end of the $\mathrm{T}$ wave is defined as the intersection between this line and the isoelectric line [15].

\section{Superimposed median beat (SMB) and automated global median beat methods}

In these methods, a "median beat" is created for all 12 leads. These beats are superimposed on each other such that they are temporally aligned. The QT is then measured from the earliest onset of the Q wave to the latest offset of the T wave [16].

It is recommended to measure more than one lead and take the median measurement $[10,17]$. The median is more reliable in comparison with the mean to minimize skewing of the central measure by any one lead. Although the tangent method has been shown to have less inter-reader variability, it may give a shorter measurement of the QT compared with the other methods and may be more inaccurate with unusual $\mathrm{T}$ wave morphology [11]. It is advisable to avoid using a single beat to measure the QT in each lead. A more accurate approach is to average 3 to 5 beats in each ECG lead to avoid beat-to-beat variation.

\section{Gender and QT interval}

Gender differences in the corrected QT interval have been noted since Bazett's initial description during the 1920s. Gender has long been considered to influence the electrocardiographic pattern of cardiac repolarization. A longer duration of repolarization, manifested by a longer QT interval, and lower T wave amplitude is present in the surface ECG of women compared to men [14,18]. It has also been reported that although in both men and women the descending limb of the $\mathrm{T}$ wave is steeper than the ascending limb, the maximum slope of each limb of the T wave is steeper in men than in women [19]. In children, QT intervals are similar in boys and girls, but the duration starts shortening after puberty in men. In adult men, individuals with higher testosterone levels such as athletes who take anabolic steroid have shorter QT interval. The same observation is made in women with virilization syndromes [20]. Bidoggia, et al. concluded that testosterone plays a vital role in modulating cardiac repolarization [21]. The reported gender difference is more significant in the younger population (12-15 $\mathrm{ms}$ in younger adult compared to $6-10 \mathrm{~ms}$ in older adults). The gender difference in rate adjusted QT interval becomes less significant after 40 years of age and almost disappears in older patients [22].

Different studies have used normal limits based on the study population and the method of calculation. In a large study, using ECG data of 11,739 normal men and women aged 40 years or older, Rautaharju, et al. concluded that normal limits established using the upper and lower limits of actual percentile distributions of the rate-adjusted QT are preferable to those from mean values $+/-2 \mathrm{x}$ standard deviation due to skewed distribution. According to the AHA/ ACCF/HRS 2009 scientific statement on recommendations for the standardization and interpretation of the electrocardiogram, prolonged QT is defined as a value of $460 \mathrm{~ms}$ or longer for women and a value of $450 \mathrm{~ms}$ or longer for men. A QT interval of $390 \mathrm{~ms}$ or shorter is defined as short QT for both genders [9].

\section{Adjustment for heart rate}

The QT interval changes with the heart rate and the interval increases as heart rate decreases. This change is the result of the change in the duration of the ventricular action potential and refractory periods. Bazett [23] and later Fridericia [24] were first to describe the relation between QT interval and heart rate in 1920. Bazett's original formula was later modified by Shipley and Hallaran [25]. Numerous other formulas have been developed over the years to correct QT interval for the heart rate (Table 1).

Most of these equations have been derived from resting ECGs and are not without imperfections. The Bazett's formula, for example, is mostly accurate for heart rates between 60 and 100 and may overcorrect at slower heart rate and under correct at faster heart rate [26]. The Fridericia formula has a similar limitation at slower heart rate, but it is more accurate with faster heart rate. Although there is no consensus, the Bazett's formula has been widely used to calculate rate-corrected QT interval (QTc). The AHA/ACCF/HRS 2009 scientific statement on recommendations for the standardization and interpretation of the electrocardiogram recommends using linear regression functions rather than the Bazett's formula for QT rate correction and that the method used for rate correction be identified in ECG analysis reports [7]. Despite this, Bazett's formula remains the most widely used method for correcting QT interval for heart rate.

\section{QT interval correction for QRS duration}

Since the QT interval encompasses the QRS, QT duration is directly affected by changes in ventricular depolarization. The QRS

Table 1. QT correction for heart rate

\begin{tabular}{|l|l|}
\hline $\begin{array}{l}\text { (Non-linear) } \\
\text { Bazett [18] }\end{array}$ & QTcB=QT/RR1/2 \\
\hline Fridericia [19] & QTcFri=QT/RR1/3 \\
\hline $\begin{array}{l}\text { (Linear) } \\
\text { Framingham [20] }\end{array}$ & QTcFra=QT+0.154 (1-RR) \\
\hline Hodges [21] & QTcH=QT+0.00175 ([60/RR]- 60) \\
\hline Rautaharju [17] & $\begin{array}{l}\text { QTcR=QT- } 0.185(\mathrm{RR}-1)+\mathrm{k}(\mathrm{k}=+0.006 \text { seconds for men and }+0 \\
\text { seconds for women })\end{array}$ \\
\hline
\end{tabular}


can be affected by many factors such as bundle branch block, preexcitation, ventricular pacing, and use of class 1C antiarrhythmic drugs. In these clinical situations, the use of JT interval, defined as QT interval duration minus QRS duration, has been advocated as a more appropriate measure of ventricular repolarization than the QT [27]. In normal conduction, the QT interval is mainly a representation of ventricular repolarization, which corresponds to the JT interval. It has also been suggested that deducting the QRS from the QTc or other heart rate correction formulas would provide a more precise measure of repolarization, particularly in patients with a wide QRS complex [28]. In a study of over 12,000 patients, Rautaharju, et al. showed that detection of prolonged repolarization in ventricular conduction delay requires the use of the JT interval or a bivariate model for QT with RR and QRS intervals as covariates [29]. This approach has been endorsed by the AHA/ACCF/HRS 2009 scientific statement on recommendations for the standardization and interpretation of the electrocardiogram. If the JT interval is chosen, normal standards explicitly established for the JT interval should be used [29]. In case of a paced rhythm, a commonly used practice is to subtract $50 \mathrm{~ms}$ from the actual measured value. Chakravarty, et al. confirmed that the 50-millisecond subtraction rule is accurate with a range of $\pm 16 \mathrm{~ms}$ at an average heart rate of 66 beats per minute. At faster heart rates, they concluded that the $50 \mathrm{~ms}$ adjustment might underestimate the QTc discrepancy between a wide and normal QRS [30].

\section{Varying RR interval and diurnal variation}

Varying RR interval in situations such as sinus arrhythmia and atrial fibrillation can pose a challenge in calculating the corrected QT interval. In sinus arrhythmia, which is common in children, variable QTc interval increases the likelihood of an erroneous diagnosis of prolonged QT, with significant implications. Adjustment of the QT interval to changes in the RR interval occurs gradually rather than instantaneously $[31,32]$. This is problematic in atrial fibrillation, and the QT measurement represents a steady-state value only when the rhythm remains regular for several cycles. The QT interval should be preferably determined during stable sinus rhythm and QT values derived from ECGs with arrhythmias should be interpreted with caution [33]. The QT interval has a diurnal variation and is longer in the evening and at night [34]. One study showed that the QT interval could change as much as $76 \mathrm{~ms}$ over 24 hours [35]. In another study, it was noted that that the QT interval was longer during sleep likely due to autonomic tone [36].

\section{Conclusion}

The QT interval measurement is one of the most critical aspects of any ECG evaluation. There are many factors such as drugs, electrolyte imbalance, ischemia and other factors that can influence the QT interval. The importance of correct measurement of the QT interval cannot be over-emphasized, given potential deadly consequences of unrecognized long QT. To measure the QT interval accurately, one needs to be aware of many factors and cannot rely solely on computer-read values.

\section{References}

1. Wolff L (1950) Electrocardiography. Fundamentals and clinical application. Philadelphia: W.B. Saunders company.

2. Romano C, Gemme G, Pongiglione R (1963) Rare cardiac arrhythmias of the pediatric age. II. Syncopal attacks due to paroxysmal ventricular fibrillation [Italian]. Clin Pediatr (Bologna) 45: 656-683. [Crossref]
3. Ward OC (1964) A new familial cardiac syndrome in children. J Ir Med Assoc 54: 103-106. [Crossref]

4. Darpo B (2010) The thorough QT/QTc study 4 years after the implementation of the ICH E14 guidance. Br J Pharmacol 159: 49-57. [Crossref]

5. Allen LaPointe N, Al-Khatib SM, Kramer JM, Battle J, Robert RM (2002) Deficits in knowledge related to the QT interval that could impact patient safety. J AM COLL CARDIOL 39: 125.

6. Viskin S (1999) Long QT syndromes and torsade de pointes, Lancet 354:1625-1633.

7. Rautaharju PM, Surawicz B, Gettes LS, Bailey JJ, Childers R, et al. (2009) AHA/ ACCF/HRS Recommendations for the Standardization and Interpretation of the Electrocardiogram Part IV: The ST Segment, T and U Waves, and the QT Interval: A Scientific Statement From the American Heart Association Electrocardiography and Arrhythmias Committee, Council on Clinical Cardiology; the American College of Cardiology Foundation; and the Heart Rhythm Society. Circulation 119: e241-e25. [Crossref]

8. Goldenberg I, Moss AJ, Zareba W (2006) QT interval: how to measure it and what is "normal." J Cardiovasc Electrophysiol 17: 333-336.

9. Kligfield P, Gettes L, Bailey JJ, Childers R, Deal BJ, et al. (2007) Recommendations for the standardization and interpretation of the electrocardiogram: part $\mathrm{I}$ : the electrocardiogram and its technology: a scientific statement from the American Heart Association Electrocardiography and Arrhythmias Committee, Council on Clinical Cardiology; the American College of Cardiology Foundation; and the Heart Rhythm Society: endorsed by the International Society for Computerized Electrocardiology. Circulation 115:1306-1324. [Crossref]

10. Malik M, Camm AJ (2001) Evaluation of drug-induced QT interval prolongation implications for drug approval and labeling. Drug Saf 24: 323-351.

11. Kasamaki Y, Ozawa Y, Ohta M, Sezai A, Yamaki T, et al. (2011) Automated versus manual measurement of the QT interval and corrected QT interval. Ann Noninvasive Electrocardiol 16: 156-164.

12. Salvi V, Karnad DR, Kerkar V, Panicker GK, Manohar D, et al. (2012) Choice of an alternative lead for QT interval measurement in serial ECGs when Lead II is not suitable for analysis. Indian Heart J 64: 535-540. [Crossref]

13. Lepeschkin E, Surawicz B (1952) The measurement of the Q-T interval of the electrocardiogram. Circulation 6: 378-388. [Crossref]

14. Merri M, Benhorin J, Alberti M, Locati E, Moss AJ (1989) Electrocardiographic quantitation of ventricular repolarization. Circulation 80: 1301-1308.

15. Salvi V, Karnad DR, Panicker GK, Natekar M, Hingorani P, et al. (2011) Comparison of 5 methods of QT interval measurements on electrocardiograms from a thorough QT/QTc study: effect on assay sensitivity and categorical outliers. J Electrocardiol 44: 96-104.

16. Badilini F, Sarapa N (2006) Implications of methodological differences in digital electrocardiogram interval measurement. J Electrocardiol 39: S152.

17. Isbister GK, Calver L, van Gorp F, Stokes B, Page CB (2009) Inter-rater reliability of manual QT measurement and prediction of abnormal QT, HR pairs. Clin Toxicol (Phila) 47: 884-888

18. Gambill CL, Wilkins ML, Haisty WK, Anderson ST, Maynard C, et al. (1995) T wave amplitudes in normal populations. Variation with ECG lead, sex, and age. $J$ Electrocardiology 28: 1917.

19. Yang H, Elko P, Fromm BS, Baga JJ, Pires LA, et al. (1997) Maximal ascending and descending slopes of the T wave in men and women. J Electrocardiology 30: 267-276.

20. Ozcan C, Cutis AB (2014) Sex Differences in Arrhythmias, In Zipes PD, Jalife J Cardiac Electrophysiology: From Cell to Bedside [6th Edn], Saunders an imprint of Elsevier Inc. p: 1053.

21. Bidoggia H, Maciel JP, Cappaloza N, Mosca S, Blaksley EJ, et al. (2000) Sex differences in the electrocardiographic pattern of cardiac repolarization. Possible role of testosterone. Am Heart $J$ 140: 678 .

22. Rautaharju P, Rautaharju F (2007) Investigative Electrocardiography in Epidemiological Studies and Clinical Trials. London, UK: Springer Verlag London Ltd p: 1- 410.

23. Bazett Hcg (1920) An analysis of the time-relations of electrocardiograms. Heart 7 353-370.

24. Fridericia LS (1920) Die systolendauer im elektrokardiogramm bei normalen menschen und bei herzkranken. Acta Med Scand 53: 469-486.

25. Shipley RA, Hallaran WR (1936) Four-Lead Electrocardiogram in 200 Normal Men and Women. Am Heart J 11: 325. 
26. Funck-Brentano C, Jaillon P (1993) Rate-corrected QT interval: techniques and limitations. Am J Cardiol 72: 17B-22B.

27. Das G (1990) QT interval and repolarization time in patients with intraventricular conduction delay. $J$ Electrocardiol 23: 49-52.

28. Spodick DH (1992) Reduction of QT-interval imprecision and variance by measuring the JT interval. Am J Cardiol 70: 628-629. [Crossref]

29. Rautaharju PM, Zhang ZM, Prineas R, Heiss G (2004) Assessment of prolonged QT and JT intervals in ventricular conduction defects. Am J Cardiol 93: 1017-1021. [Crossref]

30. Chakravarty S, Kluger J, Chhabra L, Ramu B, Coleman C (2015) Corrected QT in ventricular paced rhythms: what is the validation for commonly practiced assumptions? Cardiology 130: 207-210. [Crossref]

31. Surawicz B (1995) Electrophysiologic Basis of ECG and Cardiac Arrhythmias. Baltimore, Williams \& Wilkins.
32. Moleiro F, Castellanos A, Diaz JO, Myerburg RJ (2003) Dynamics of QT intervals encompassing secondary repolarization abnormalities during sudden but transient lengthening of the RR intervals. Am J Cardiol 91: 883.

33. Postema PG, Wilde AA (2014) The Measurement of the QT Interval. Curr Cardiol Rev 10: 287-294. [Crossref]

34. Bexton RS, Vallin HO, Camm AJ (1986) Diurnal variation of the QR interval: influence of the autonomic nervous system. Br Heart J 55: 253. [Crossref]

35. Morganroth J, Brozovich FV, McDonald JT, Jacobs RA (1991) Variability of the QT measurement in healthy men, with implications for selection of an abnormal QT value to predict drug toxicity and proarrhythmia. Am J Cardiol 67: 774

36. Viitasalo M, Karlajinen J (1992) QT intervals at heart rates from 50 to 120 beats/min during 24-hour electrocardiographic recordings in 100 healthy men: effects of atenolol. Circulation 86: 1439.

Copyright: (C2019 Naderi A. This is an open-access article distributed under the terms of the Creative Commons Attribution License, which permits unrestricted use, distribution, and reproduction in any medium, provided the original author and source are credited. 